\title{
Deaf Children and Adolescents: Social Skills Discriminant Profile
}

\author{
Rafaela Fava de Quevedo* (1) \& Ilana Andretta (1) \\ Universidade do Vale do Rio dos Sinos, São Leopoldo, RS, Brazil
}

\begin{abstract}
The objectives of the study were to compare social skills among deaf children and adolescents and to outline the discriminant profile in relation to skilled social behaviors. The research had a quantitative, cross-sectional and comparative design. Seventy-one deaf people aged 7 to 16 years old participated in the study, assessed by a sociodemographic questionnaire and by the Social Skills Test for Children and Adolescents in School Situation. Results revealed that deaf adolescents have more elaborate social skills when compared to deaf children. Children have a profile related to the Conversation and Social Resourcefulness and Assertiveness while adolescents were included in the Civility and Altruism profile. These results were discussed based on the development and specificities of deafness. Future research may assess these skills beyond the school settings.
\end{abstract}

KEYWORDS: social skills, deafness, discriminant analysis

\section{Crianças e Adolescentes Surdos: Perfil Discriminante de Habilidades Sociais}

\begin{abstract}
RESUMO - Os objetivos do estudo foram comparar as habilidades sociais entre crianças e adolescentes surdos e traçar o perfil discriminante em relação aos comportamentos sociais habilidosos. A pesquisa possuiu delineamento quantitativo, transversal e comparativo. Participaram 71 surdos de 7 a 16 anos, avaliados por um questionário sociodemográfico e pelo Teste de Habilidades Sociais para Crianças e Adolescentes em Situação Escolar. Os resultados revelaram que adolescentes surdos possuem habilidades sociais mais elaboradas quando comparadas às crianças surdas. As crianças possuem perfil conexo a Conversação e Desenvoltura Social e Assertividade enquanto os adolescentes incluíram-se no perfil de Civilidade e Altruísmo. Estes resultados foram discutidos a partir do desenvolvimento e especificidades da surdez. Futuras pesquisas podem avaliar essas habilidades em contextos além do escolar.
\end{abstract}

PALAVRAS-CHAVE: habilidades sociais, surdez, análise discriminante

The repertoire of social skills is defined by the manner an individual behaves in social interactions in a given context or situation. The social behaviors include characteristics related to each other, such as, giving opinions in an assertive way, giving and receiving praise, accepting criticism, defending rights of oneself and the other, initiating and maintaining conversations, and other behaviors that involve social interactions (Antia \& Kreimeyer, 2015; Caballo, 2003; Del Prette \& Del Prette, 2017). Because these are behaviors emitted in social interactions, the social skills consist of a set of acting skills learned and reinforced by the different contexts in which the individual is inserted. Thus, a social behavior suitable for a given environment may not be for another (Antia \& Kreimeyer, 2015; Caballo, 2003; Del Prette $\&$ Del Prette, 2017).

In the decision-making process regarding the response to be issued by the individual, there is a decoding of the input stimuli and the interpretation of the situation. The expression Social Skills involves specific capacities for the competent execution to take place. On the other hand, the execution of the conduct and its quality of adequacy is conceptualized as a social competence (Caballo, 2003). The social competence is an indicator related to the psychosocial adjustment, with positive consequences attributed to the development,

\footnotetext{
*E-mail: rafaelafaq@msn.com

- Submetido: 28/05/2018; Revisado: 23/01/2018; Aceito: 25/04/2020.
} 
formation and maintenance of positive relationships (Del Prette \& Del Prette, 2017).

Social behaviors can be understood in dimensions. According to Bartholomeu et al. (2014), these may be understood in three factors that encompass social skills. Regarding the first factor, Civility and Altruism, it is considered behaviors of giving and accepting praise, apologizing, helping friends, expressing positive feelings and politeness when expressing opinions. Referring to Conversation and Social Resourcefulness, behaviors of exposure to new social situations which may reverberate in embarrassment are estimated, such as receiving criticism, speaking in public, initiating and ending a conversation and interacting with a stranger. In the third factor, Assertiveness with Confrontation, the indicators refer to issues related to expressing displeasure, defending rights and opinions, negotiating under pressure from the group and affirming self-esteem. All of these behaviors are always presented at the expense of a given social context.

Social skilled behaviors involve the emission of strategies to deal assertively in different contexts that involve social interactions (Caballo, 2003). Children and adolescents have differences in the emission of these behaviors, since there are development variables that are intervening in the acquisition and development of social skills, such as age, biological maturity and the participation in different social contexts (Boyer \& Nelson, 2015; Leme et al., 2016; Papalia \& Feldman, 2013; Silva \& Cavalcante, 2015). No less relevant, the influence of other social agents, such as colleagues and teachers in the school environment are crucial for the development of social behavior, since the relationships between a child and his or her teacher differ from the relationship of an adolescent with his or her teacher (Casalli \& Costa, 2017; Semrud-Clikeman, 2007).

Considering the differences among the age groups, the social skills are distinguished as to their acquisition and development. Children and adolescents learn these skills as their emotional maturity also follows. Semrud-Clikeman (2007) states that between 6 and 11 years old, considered as third childhood or school age, children begin their schooling period, which will provide involvement with their peers and, thus, result in basic social skills. For example, behaviors related to cooperative play stand out, which require the skills to listen to each other, wait for your turn, ability to differentiate oneself from the others (interpersonal perception), non-verbal comprehension among peers and recognition of facial expressions with which they interact. This set of behaviors wrapped in the emotional development favors social skills to be properly acquired by these children. Also, the increase of the communicational repertoire is noteworthy, which collaborates with social interactions (Papalia \& Feldman, 2013).

Variables related to the parenting styles also outline great importance in children's social configuration, as they observe the way parents interact with each other, as well with the opportunities that the family will offer the child to interact, play and have social experiences with their peers, beyond the school context. However, if the child experiences isolation situations or difficulties in deciphering social interactions, it is likely that he or she will present issues in the effectiveness of the relationship with the peers, and social skills learning failures may occur (Semrud-Clikeman, 2007).

Regarding adolescence, period beginning at 12 years of age, comprehension of other people's beliefs skills are outlined, as well as motivation to modify their interaction behaviors according to the situations and groups they take part. These skills coincide with the brain development of this stage, contributing to abstract thinking and different problem solving strategies. The adolescence's psychological development also includes factors that favor social skills, such as self-perception, recognition of more complex emotions and change of thoughts and behaviors facing specific interactions. These schemes start to be stored facing already experienced situations and reorganized with new alternatives that are evaluated for the execution of new social behaviors. The relationship with the peers provided by the school setting favors social dynamics, especially as it articulates validation of assertive behaviors promoting self-esteem, sense of identity and social skills improvement (Papalia \& Feldman, 2013; Semrud-Clikeman, 2007).

Social skills are needed for the development of social relationships (Antia \& Kreimeyer, 2015; Semrud-Clikeman, 2007). Social learning will start within the family context, and when receiving a deaf child, the family communication will become particularly sensitive, since in many cases it involves the acquisition of sign language, in order to ease the socialization and solidify social bonds (Gianoto et al., 2016; Karnopp et al., 2011; Quevedo et al., 2017). In the occurrence of the birth of a deaf child in hearing families, the importance of learning the Brazilian Sign Language - Libras by the hearing family is emphasized, since the difficulty in acquiring sign language, as the delay identifying deafness may result in an impoverished social environment, consequently generating greater social dependence and emotional issues due to the distance to establish affection bonds (Gianoto et al., 2016; Marschark \& Spencer, 2011).

On one hand, deafness is not an obstacle for language when it comes to communication itself, since the sign language is the opening for the social integration of the deaf (Gianoto et al., 2016; Karnopp et al., 2011; Quevedo et al., 2017). On the other hand, deafness can be an obstacle if there is no access to language in the visual-spatial modality. It is from the schooling process that the child will establish different social experiences that are important for the development of social behaviors (Antia \& Kreimeyer, 2015; Martins, 2012). Therefore, the proposal of the bilingual education for the deaf, supported by the Linguistic Policy for Bilingual Education - Brazilian Sign Language (Libras) and Portuguese Language endorse that the school must be a place that provides contact with the natural language of 
the deaf, that is, the sign language, has deaf professionals and trained bilingual listeners, as well as adaptations in the learning curriculum for the deaf student. Bilingual education is understood as the schooling that respects the deaf identity and its visual experience as constituent of a singular culture, the Deaf Culture (Martins \& Lacerda, 2016; Stürmer \& Thoma, 2015). Given this educational perspective, it is emphasized that the socialization processes of a deaf child will be better elaborate given the coexistence with their peers, from the use of their natural language as means of communication and learning (Karnopp, Klein, \& LunardiLazzarin, 2011; Martins, 2012; Stürmer \& Thoma, 2015). Therefore, the delayed exposure may cause issues in terms of acquisition and development of social skills.

The importance of social development of the deaf with peers is well documented, with social skills gradually increasing according to the perception of friendship, acceptance among peers and social participation (Michelson et al., 1983). Still, it is worth noting that the degree of acquisition and responsiveness is related to the social environment in which the child or adolescent participates (Michelson, et al., 1983; Semrud-Clikeman, 2007), since they result from the social validation processes, natural for any individual due to their social skills.

In view of the development of characteristics for the periods of life, social skills differ between childhood and adolescence. Considering the social relationships network that will be established in the school context, it is necessary to comprehend aspects of the social development of deaf children and adolescents, who will live with their peers, having in sight dimensions of the social skills used by these age groups. Casali and Costa (2017) assessed the social skills of 15 deaf students between 6 and 17 years old, from the teachers' point of view, resulting in the majority having a median repertoire of social skills. However, deaf children from 6 to 12 years old were assessed with an inferior repertoire in these skills. Thus, it is clear that there are differences in the abilities of deaf children and adolescents, however, it should be noted that the sample size of the study, as well as the evaluation from others' perspective makes generalizations unfeasible. Likewise, the study by Streng and Kirk (1938) stand out as one of the first published works on this regard, which assessed 97 deaf oralized children between 6 and 18 years old. Although in general these deaf people presented average social skills, there were inconclusive results on the differences between age groups of children and adolescents for skilled social behaviors of these participants.

Understanding the development of social interaction of a deaf person requires innovative studies for these people such as, for example, contributions that analyze specific social behaviors in different stages of human development, considering the emerging unanswered fundamental questions regarding the communication of the deaf people (Brice \& Strauss, 2016; Wake \& Carew, 2016). Previous studies addressing social skills of people with deafness are scarce, reverberating in gaps to be studied (Antia \& Kreimeyer, 2015; Del Prette \& Del Prette, 2017; Marschark \& Spencer, 2011). From the research carried out to the date, the instruments generally are applied with the parents and/or teachers, which limits the assessment according to the perception of those who coexist with the child (Casalli \& Costa, 2017). Hence, it is necessary to assess the social skills with instruments that are applied directly to the children and adolescents taking into account their perception, not the perception of others. From the gaps presented by the literature and the need to comprehend the social behaviors in deaf people belonging to the bilingual school, the objectives of this study can be divided in two: (a) to compare social skills between deaf children and adolescents that use sign language and (b) to outline a discriminant profile between children and adolescents in this specific population in relation to the skilled social behaviors of each group.

\section{METHOD}

\section{Participants}

The sample consisted of 71 deaf children and adolescents aged between 7 and 16 years old, divided in two groups according to their age: participants between seven and 11 years old belonged to the children's group ( $n=26,36.6 \%)$, and had an average age of 8.88 years $(S D=1.33)$ and participants between 12 and 16 years old were included in the adolescents group ( $n=45,63.4 \%)$, with an average age of 13.6 years $(S D=1.36)$. All of deaf participants in the sample communicated by sign language and came from hearing families.
The participants were enrolled in four public bilingual schools in the metropolitan area and in the mountain range of the State of Rio Grande do Sul, Brazil. Thus, 42.3\% $(n=29)$ participants were in the early years of elementary school $\left(1^{\text {st }}\right.$ to $5^{\text {th }}$ Grade), $52.1 \%(n=38)$ were enrolled in the final years of elementary school $\left(6^{\text {th }}\right.$ to $9^{\text {th }}$ Grade $)$ and $5.6 \%(n=4)$ were in high school. Most participants never repeated a year $(70.4 \%$, $n=50$ ), always studied in special schools for deaf students $(63.4 \%, \mathrm{n}=45)$ and belong to the Economic Classes C, D and $\mathrm{E}(83 \%, n=59)$, according to the Brazilian Association of Research Companies (ABEP, 2016) classification. It is important to point out that adolescents with other diagnosis 
involving cognitive impairment previously diagnosed were not part of the sample, which was informed by the family or school, as well as those beyond or below the established age group $(n=105)$, or by the non-consent of the person responsible for the child participation in this research $(n=12)$.

\section{Instruments}

\section{Sociodemographic Questionnaire}

It was developed to know specificities of the sample population, such as age, sex, education and syndromes diagnoses, cognitive impairment, among others. In addition, information on the participants' socioeconomic classification was addressed, according to the Brazilian Criteria (ABEP, 2016).

\section{Test of Social Skills for Children and Adolescents in School Settings (THAS-C)}

It is an instrument created by Bartholomeu et al. (2014) that assesses social skills in the school context of children between 7 and 15 years old, however, the possibility of applying it to 16 years old adolescents was carefully discussed with the authors. It is a three-point likert scale always, sometimes and never, composed of 23 items that evaluate 3 factors: Civility and Altruism (13 items), Conversation and Social Resourcefulness (6 items), and Assertiveness with Confrontation (4 items). The gross score is translated into percentiles provided by ages, generating classifications that vary from Very Low Social Skills (Quartile below 25) and Very High Social Skills (Quartile above 75). The precision coefficients provided indexes of 0.83 for Cronbach's alpha (Bartholomeu et al., 2014). For the present study, the reliability index was 0.87 for alpha.

The instrument was carried out individually, from 15 to 30 minutes, in a room provided in each school, with the presence of a Libras Interpreter Translator. In order to the instrument become more sensitive, there was a need to adapt the content of Libras in terms of the participants' age together with a deaf educator. Andrade and Castro (2016) confirm the need for adapted instruments to sign language, since the deaf population has the right to be assessed according to their mother tongue, reverberating in respect for their cultural specificities. The choice for an instrument to assess social skills in school settings was due the fact that assessment context must be naturalistic (Del Prette \& Del Prette, 2017), that is, an environment that is real to what the participants experience.

\section{Ethical and data collection procedures}

Contact was made with educational institutions, initially seeking the consent of a school for the deaf. After the approval by the Research Ethics Committee of the University of Vale do Rio dos Sinos (UNISINOS), registered under number 1.917.775, the educational institutions for deaf children were reached out by telephone, with four accepting to participate. In most schools, the management team contacted the families, sending the Free and Informed Consent Form (TCLE) and the Sociodemographic Questionnaire to those responsible. With each child and adolescent, rapport was made, and the instrument transferred to Libras with a Libras Interpreter Translator was applied, as well as the signing of the Term of Assent.

\section{Data analysis}

The data were analyzed with the software Statistical Package for the Social Sciences (SPSS), version 22.0 (IBM Corporation, 2013) by descriptive analysis (mean, standard deviation, frequency) and group comparison, opting for the Student's $t$-test, considering the significance level of 5\% (Field, 2016; Sampieri et al., 2013). For the inferential analyzes, the Kolmogorov-Smirnov test was used, in which the homogeneous distribution was verified.

To trace a discriminant profile among deaf children and adolescents, the multivariate technique of discriminant analysis was used. This type of statistical analysis is applied in situations where the sample can be divided in groups based on a dependent variable, in this case considering the child and adolescent age groups. The objectives of this analysis aim to understand the difference between groups, making it possible to predict the probability for an individual to belong to a particular profile based on the independent variables (Hair et al., 2009). Therefore, the social behaviors and social skill factors that are, statistically, more associated with the children's or adolescents' group were pointed out.

\section{RESULTS}

The comparison of the children's and adolescents' subgroups made it possible to verify differences between the groups, with deaf adolescents presenting higher average scores for Civility and Altruism, Assertiveness with Confrontation as well as in the General Social Skills Classification. On the other hand, no differences were identified in the Conversation and Social Resourcefulness (Table 1).

Bearing in mind that deaf adolescents are more socially skilled than deaf children, a discriminant analysis was carried out in order to verify the socially skilled behaviors that identify each group. Thus, the function obtained in the discriminant 
profile between the age groups, as it is unique, explains 100\% of the variability between groups. The discriminant function is significant $(\chi 2=10.734, p=0.005)$ and has a canonical discriminant correlation of 0.382 (Table 2 ).

It is possible to observe a Wilks' $\lambda$ of 0.854 , equivalent to a variance explained by the discriminant function of $17.1 \%$. Regarding the classification, the function obtained correctly classifies $69.0 \%$ of the participants in their corresponding groups, being a good predictive classification index through the profile of the function obtained (Table 3).

The children's group had a centroid value of 0.530 , whereas the adolescents' group had a -0.310 value. These values indicate that the groups are greatly distant from the profile obtained, being able to be discriminated by the presented variables, considering that the sign of the obtained correlations indicates the direction favorable to one group or the other. The significant and most important variables in the discriminative capacity between the children's and adolescents' age groups are sorted by the absolute correlation size in the structural matrix, with a cutoff point of 0.200 (Table 4).

Table 1

Comparison of social skills between deaf children and adolescents

\begin{tabular}{|c|c|c|c|c|}
\hline & & Mean $(S D)$ & $t$ & $p$ \\
\hline \multirow{2}{*}{ Factor 1 - Civility and Altruism } & Child & $3.12(2.06)$ & -5.273 & $0.001^{*}$ \\
\hline & Adolescent & $5.42(1.61)$ & & \\
\hline \multirow{2}{*}{ Factor 2 - Conversation and Social Resourcefulness } & Child & $3.50(2.42)$ & -0.130 & 0.897 \\
\hline & Adolescent & $3.58(2.46)$ & & \\
\hline \multirow{2}{*}{ Factor 3 - Assertiveness with Confrontation } & Child & $3.46(2.04)$ & -2.049 & $0.039 *$ \\
\hline & Adolescent & $4.58(2.30)$ & & \\
\hline \multirow{2}{*}{ THASC - SS General Classification } & Child & $2.96(2.49)$ & -6.438 & $0.001 *$ \\
\hline & Adolescent & $5.80(1.21)$ & & \\
\hline
\end{tabular}

Note. Student's t-test for independent samples. ${ }^{*} p<0.05$

Table 2

Discriminant function values between deaf children and adolescents

\begin{tabular}{ccccccc}
\hline Function & Own Value & $\begin{array}{c}\text { Variance } \\
\text { percentage }\end{array}$ & $\begin{array}{c}\text { Canonical } \\
\text { Correlation }\end{array}$ & Wilks $\boldsymbol{\lambda}$ & $\boldsymbol{p}$ & $\boldsymbol{D}$ \\
\hline 1 & 0.171 & 100.0 & 0.382 & 0.854 & 10.734 & 2 \\
\hline
\end{tabular}

Note. Values of the obtained function

Table 3

Values of the discriminant classification between deaf children and adolescents

\begin{tabular}{lccc}
\hline & Child & Adolescent & Total \\
\hline Child & $73.1 \%$ & $26.9 \%$ & $100 \%$ \\
Adolescent & $33.3 \%$ & $66.7 \%$ & $100 \%$ \\
\hline
\end{tabular}

Note. Group classification: $69 \%$ of the original cases were correctly classified

Of the 23 social behaviors of THAS-C, eight were discriminated between the groups, as shown in Table 4. The behaviors that most discriminate between the groups were shame in speaking to the whole class $(0.685)$ considering the deaf children's group, and helping friends in need (-0.685), in the deaf adolescents' group. With moderate discrimination power between groups, the behaviors of shame arriving in an unknown group (0.410), feeling anger when criticized even if fairly (0.369), shame in asking a stranger something $(0.220)$ and speaking up when a friend says something they do not like (0.210) appeared in the children's group.

On the other hand, behaviors associated with being kind to friends in the classroom (-0.259) and praising a friend $(-0.224)$ leaned with moderate power in the deaf adolescents' group. In this matter, it is possible to observe that the values that most discriminate children and adolescents are associated with Conversation and Social Resourcefulness and to Assertiveness with Confrontation. In addition, the values referring to greater skills functionality in Civility and Altruism discriminate groups in favor of adolescents. 
Discriminated social behaviors between deaf children and adolescents

\begin{tabular}{lc}
\hline & Function 1 \\
\hline Shame to speak to the whole classroom & 0.685 \\
Helping friends in need & -0.606 \\
Shame arriving in an unknown group & 0.410 \\
Feeling anger when criticized even if fairly & 0.369 \\
Being kind to friends in the classroom & -0.259 \\
Praising a friend & -0.224 \\
Shame in asking a stranger something & 0.220 \\
Speaking up when a friend says something they do not like & 0.210 \\
\hline
\end{tabular}

Note. Structural matrix of the canonical discriminant function. Negative centroids (-) indicated deaf adolescents and positive centroids (+) targeted deaf children.

\section{DISCUSSION}

The results suggest that there are differences between the age groups regarding social skills, with deaf adolescents having higher levels of social skills when compared to deaf children, corroborating with the results of Casalli and Costa (2017) and advancing inconclusive results (Streng \& Kirk, 1938). The result also confirms studies that show that as age progresses, an increase in the social skills repertoire occurs and this is reproduced in the groups of children and adolescents (Boyer \& Nelson, 2015; Semrud-Clikeman, 2007; Silva \& Cavalcante, 2015). In view of this, it should be noted that deaf children had lower scores of social skills because they experienced fewer social interactions when compared to deaf adolescents. The latter begins to experience a greater number of social relationships based on the age development and the more active participation in different settings. This is because adolescents have greater autonomy in relation to children who will depend on the contexts that the family interacts for the acquisition and development of the social repertoire (Antia \& Kreimeyer, 2015; Lobo, 2016; Semrud-Clikeman, 2007).

Although it is not the only factor, it is from the communication development that the production of meaning is made in a deaf person's social interaction (Batten et al., 2014; Karnopp et al., 2011; Marschark \& Spencer, 2011; Martins, 2012). The deaf adolescents that participated in this sample, presenting higher social skills when compared to deaf children, show greater maturity in communication, possibly due the development of Libras. From this, it is possible to understand that the evolution of interaction occurs between their equals, that is, those who share the Deaf Culture, as well as the sign language, revealing continuous reinforcement in the formation and constancy of these deaf adolescents' social skills (Lobo, 2016).

The relationship among peers promotes crucial experiences for the deaf adolescent, given the motivation and interests and activities in common for the development of new social skills, such asthe negotiation skill, which permeates the learning in the family nucleus (Antia \& Kreimeyer, 2015; Lobo, 2016; Semrud-Clikeman, 2007). Adolescents spend more time with their friends, with whom they have common interests and beliefs, which favors a feeling of equality and reciprocity (Antia \& Kreimeyer, 2015; Batten, et al., 2014). As he develops interactions and friendship bonds, the adolescent also learns how to solve conflicts with each other (Antia \& Kreimeyer, 2015; Del Prette \& Del Prette, 2017; Lobo, 2016; Semrud-Clikeman, 2007), and these psychosocial stimuli value the skills of Assertiveness with Confrontation in a more positive manner. Still, it is emphasized that the adolescent, with the age development, already possesses greater cognitive maturity to recognize emotions (Del Prette \& Del Prette, 2017; Semrud-Clikeman, 2007), to interpret the other and the social situation that is presented and to act specifically in relation to the interaction being experienced (Antia \& Kreimeyer, 2015). Thus, cognitive maturity and social experiences allow multiple opportunities to evaluate, select and test social behaviors with others in different contexts.

Regarding Conversation and Social Resourcefulness, there were no statistically significant differences between the children's and adolescent's group. It is noticed that all the participants had a repertoire of skills below the average in this factor. Bartholomeu et al. (2014) point out that this factor involves social conducts with a higher difficulty degree for its emission in a social context, since they present moral components, including the presence of regulatory emotions, such as the shame of exposing oneself to others. Corroborating the instrument's validation norm, this dimension, in the present study, is the one with the highest difficulty level, both for deaf children's and adolescents' group. Papalia and Feldman (2013) state that, in the third childhood and in adolescence, shame becomes internalized, as well as the ability to regulate negative emotions. 
However, this result was not observed in deaf children and adolescents. It is emphasized that this may be a risk factor for this population, since the difficulties in this dimension promote embarrassment in exposure situations, preventing the initiative taking and causing significant social damage (Bartholomeu, et al., 2014; Del Prette \& Del Prette, 2017).

Bearing in mind the differences presented between the age groups, the social behaviors contrasting these deaf children and adolescents in the school setting were also presented. Thus, the discriminant profile of deaf children and adolescents showed that the participants in the children's group sample presented a profile of social behaviors of their own: shame to speak in front of the whole classroom; shame to arrive in an unknown group; feeling anger when criticized even if fairly; shame in asking a stranger something; speaking up when a friend says something they do not like. Except for the last item that involves skills of Assertiveness with Confrontation, the other social behaviors are related to Conversation and Social Resourcefulness.

Facing these characteristics, it is possible to state that the deaf children in the sample present social behaviors typical of hearing children, expressing their emotions and social actions with less resourcefulness and adaptive choice (Marschark \& Spencer, 2011). It is noteworthy that social skills differ in relation to the child's or adolescent's age, being more or less important and used to a greater degree, according to their interactions (Antia \& Kreimeyer, 2015; Semrud-Clikeman, 2007). Just as the level of difficulty in acquiring and performing these skills varies, Civility and Altruism are the easiest dimension and Conversation and Social Resourcefulness the hardest factor (Bartholomeu, et al., 2014).

The deaf children in the sample also showed the behavior of speaking up when a friend says something they do not like. However, it is noteworthy that the way this behavior is performed may be less assertive, since the fluency in the communication is still restricted and these children are learning how to interact with their peers in the school setting (Antia \& Kreimeyer, 2015; Marschark, et al., 2014; Martins, 2012). From another perspective, it shows that Assertiveness with Confrontation skills are being learned and developed, fundamental for the social interactions in relation to respect their interests and the defense of their rights and opinions (Bartholomeu, et al., 2014; Del Prette \& Del Prette, 2017; Semrud-Clikeman, 2007). Because it is a moderate level of performance, social behaviors that involve the Assertiveness with Confrontation dimension can be acquired later (Bartholomeu, et al., 2014), but the children from the sample already present this behavior as characteristic for their age.
On the other hand, the profile that discriminates deaf adolescents in relation to children involves the following social behaviors, namely: helping friends in need; being kind to friends in the classroom; and praising a friend. In view of these social behaviors, it stands out that all of them belong to the Civility and Altruism category. This skills category involves the easiest behaviors to be emitted and indicate that these deaf adolescents grasp the most basic rules of social conduct, which favors their socialization (Bartholomeu et al., 2014). Over time, supported by the school insertion, the deaf adolescent shows a cognitive growth as well as the influence of friends and of the school itself, posing as models for the development of social skills related to greater politeness in their expressions with others (Antia \& Kreimeyer, 2015; Marschark \& Spencer, 2011; Papalia \& Feldman, 2013; Semrud-Clikeman, 2007). The groups that the deaf adolescents will participate assist in several functions, including emotional support, validation, source of information, advice, feeling of solidarity, moral development and social standard. Therefore, it is important for the adolescent to feel connected with other deaf people in specific settings where they feel comfortable to discover interactions, as well as being socially recognized in a more positive manner by colleagues and adults (Del Prette \& Del Prette, 2017; Karnopp et al., 2011; Lobo, 2016; Marschark $\&$ Spencer, 2011; Martins, 2012; Semrud-Clikeman, 2007). Thus, it is highlighted that the results of the present study are supported by the literature, in which factors related to friendship development and to participation in contexts that favor communication are closely connected to the skills of Civility and Altruism, which is expected in the adolescence phase (Papalia \& Feldman, 2013; SemrudClikeman, 2007).

The school and the deaf community can be facilitators in the process of social skills acquisition for the deaf, since deaf teachers or listeners who use the sign language are models for these children and adolescents. Thus, the bilingual school and inclusion spaces for the deaf are important and can promote programs and activities mediating the socialization of the deaf for a better performance in social relationships (Batten, et al., 2014; Del Prette \& Del Prette, 2017; Karnopp et al., 2011; Lobo, 2016; Marschark \& Spencer, 2011). As a result of the active participation in the deaf community and the increased social bonds, the adolescent has a more elaborate feeling of self-recognition about his deaf identity (Brice \& Strauss, 2016; Lobo, 2016; Marschark \& Spencer, 2011). Consequently, this adolescent will have greater chances of developing civil behaviors and reciprocity to his peers, according to the results from this sample, who participate in the bilingual school. 


\section{CONCLUSION}

Considering the objectives of the present study, it became evident that deaf adolescents have a wider repertoire of social skills compared to deaf children, as well as children present social behaviors related to Conversation and Social Resourcefulness and Assertiveness with Confrontation and adolescents have a profile connected to Civility and Altruism. The results are important to understand the social behavior variables that explain the social development of social skills in deaf individuals who communicate using sign language. The specificity of the sample allowed the articulation of the results for these deaf people, considering differences such as if these deaf people were oralized when possible, or yet, if they were enrolled in inclusive schools in which the relationships would be mediated by the Libras interpreter.

Social skills, because they rely on a context to be appropriate or not, must be assessed within the culture and consider the individual's particularities (Antia \& Kreimeyer, 2015; Del Prette \& Del Prette, 2017; Lobo, 2016). It is important to highlight that the results of this research come from deaf children and adolescents from hearing families, thus belonging to the hearing culture and the Deaf Culture (Antia \& Kreimeyer, 2015; Karnopp et al., 2011). These children and adolescents can become emotionally and socially competent, if given the opportunities for the development of the awareness, independent thinking, skill and competency for problem solving, social identity and promotion of life quality for the deaf (Batten, et al., 2014; Brice \& Strauss, 2016; Lobo, 2016; Marschark \& Spencer, 2011; Semrud-Clikeman, 2007). This will happen especially if these skills are reinforced by the family, teachers and professionals who interact with the deaf children and adolescents, allowing these deaf young people to participate in the acquisition and development process of social competence. It is emphasized that all those involved must be connected, since the sense of belonging and recognition can contribute for the development and social adaptation of deaf children and adolescent, acting in the best life quality of this population (Brice \& Strauss, 2016; Del Prette \& Del Prette; 2017; Marschark \& Spencer, 2011).

Facing the limitations of the study, there is a need to assess the social skills including instruments that include other variables related to deafness, such as the levels of hearing loss, period of identification of the deafness and the types of deafness (congenital or acquired), as these may be intervening variables for these social skills. In addition, these results are limited to social skills targeted in the school setting, making it necessary to include the social behavior of these deaf participants who come from other environments. Yet, the non-use of instruments to assess cognitive deficits in these participants limits the results to what the children's responsible person claims about their diagnosis, since this information was acquired by the answer of these parents. No less important, the specific geographic concentration of only one State in the country and the sample size stand out, which may be considered small to suggest generalizations, although it is known that deaf people are a minority in the general population. In any case, it is an innovative study and promoted relevant results for the understanding of these participants' sociability.

It is suggested that future research covers the context of social skills in the deaf population, including other settings other than the school, identifying whether these social behaviors continue to characterize the age groups included in this study. Also, it is recommended that a comparison study to be carried out with the hearing population in relation to the deaf, showing if there are differences in these profiles of social behaviors or if they match up.

\section{REFERENCES}

Associação Brasileira de Empresas de Pesquisa (2016). Critério Brasil 2016 [Brazil Criterion 2016]. http://www.abep.org/ download

Andrade, L. F., \& Castro, S. S. (2016). Saúde e surdez: instrumentos de pesquisas adaptados à língua de sinais - uma revisão sistemática [Health and hearing: Research instruments adapted to sign language - a systematic review]. Medicina (Ribeirão Preto Online) 49(2), 175-184. https://doi.org/10.11606/ issn.2176-7262.v49i2p175-184

Antia, S. D., \& Kreimeyer, K. H. (2015). Social competence of deaf and hard-of-hearing children. Professional Perspectives on Deafness: evidence and applications. Oxford University Press.

Bartholomeu, D. Silva, M. C. R., \& Montiel, J. M. (2014). Teste de habilidades sociais para crianças e adolescentes em situação escolar - manual [Social skills test for school children and adolescents - manual]. Memnon.

Batten, G., Oakes, P. M., \& Alexander, T. (2014). Factors associated with social interactions between deaf children and their hearing peers: A systematic literature review. Journal of Deaf Studies and Deaf Education, 19(3), 285-302. https://doi.org/10.1093/ deafed/ent052

Boyer, B. P., \& Nelson, J. A. (2015). Longitudinal associations of childhood parenting and adolescent health: The mediating influence of social competence. Child Development, 86(3), 828-843. https://doi.org/10.1111/cdev.12347

Brice, P. J., \& Strauss, G. (2016). Deaf adolescents in a hearing world: a review of factors affecting psychosocial adaptation. Adolescent Health, Medicine and Therapeutics, 7(67). https:// doi.org/10.2147/AHMT.S60261

Caballo, V. E. (2003). Manual de avaliação e treinamento das habilidades sociais [Social skills assessment and training manual]. Livraria Santos.

Casalli, A. C. P., \& Costa, C. S. L. (2017). Habilidades sociais de alunos surdos na perspectiva de professores da classe bilíngue, da classe comum e intérprete [Social skills of deaf students in teacher perspective of bilingual class, regular class and 
interpreter]. Revista Educação Especial, 30(57), 55-67. https:// doi.org/10.5902/1984686X20286

Del Prette, Z. A. P. \& Del Prette, A. (2017). Psicologia das habilidades sociais na infância: teoria e prática [Psicologia das habilidades sociais na infância: teoria e prática]. (5 ${ }^{\mathrm{a}}$ ed.). Vozes.

Field, A. (2016). Discovering statistics using IBM SPSS Statistics ( $4^{\mathrm{a}}$ ed.). Sage.

Gianoto, H. D. S. S., Gianotto, A. O., \& Marques, H. R. (2016). Pais ouvintes, filhos surdos: barreiras na comunicação [Listeners deaf, children parents:

barriers in communication]. Multitemas, 21(49), 161-180. https:// doi.org/10.20435/multi.v21i49.1114

Hair Jr., J.F., Black, W.C., Babin, B.J., Anderson, R.E., \& Tatham, R.L. (2009). Análise multivariada de dados [Análise multivariada de dados]. (6 $6^{\mathrm{a}}$ ed.). A. S. Sant'Anna [Trad.]. Bookman.

IBM Corporation (2013). IBM SPSS Statistics for Windows (versão 22.0) [Progama de Computador]. IBM Corp.

Karnopp, L., Klein, M. \& Lunardi-Lazzarin, M. L. (Orgs.) (2011). Cultura surda na contemporaneidade: negociações, intercorrências e provocações [Deaf culture in contemporary times: negotiations, complications and provocations]. ULBRA.

Leme, V. B. R., Del Prette, Z. A. P., Koller, S. H., \& Del Prette, A. (2016). Habilidades sociais e o modelo bioecológico do desenvolvimento humano: Análise e perspectivas [social skills and bioecological model of human development: Analyze and perspectives]. Psicologia \& Sociedade, 28(1), 181-193. https:// doi.org/10.1590/1807-03102015aop001

Lobo, M. C. (2016). Adolescente surdo e os conflitos da idade: o olhar da Psicologia [Deaf adolescent and age conflicts: The look of Psychology]. Revista Núcleo de Estudos Paranaenses da UFPR, 2(5), 132-143. https://doi.org/10.5380/nep.v2i5.49565

Martins, C. R. (2012). A cultura surda na escola [Deaf culture at school]. In: G. Perlin \& M. Stumpf (Orgs). Um olhar sobre nós surdos: Leituras contemporâneas (pp. 159-166). CRV.

Martins, V. R. O., \& Lacerda, C. B. F. (2016). Educação inclusiva bilíngue para surdos: problematizações acerca das políticas educacionais e linguísticas [Inclusive bilingual education of deaf children: An analysis of education and language policies].
Revista de Educação PUC-Campinas, 21(2), 163-178. https:// doi.org/10.24220/2318-0870v21n2a3277

Marschark, M., \& Spencer, P. E. (2011). The Oxford handbook of deaf studies, language, and education ( $2^{\mathrm{a}}$ ed., Vol.1). Oxford University Press.

Michelson, L., Sugai, D. P., Wood, R. P., \& Kazdin, A. E. (1983). Social Skills Assessment and Training with Children: An empirically based handbook. Springer.

Papalia, D. E., \& Feldman, R. D. (2013). Desenvolvimento humano [Human development] (12a ed.). Artmed.

Quevedo, R. F., Dambrós, S., \& Sassi, R. (2017). Grupo de mães ouvintes de filhos surdos: relato de uma experiência de estágio [Group of hearing mothers of deaf children: Internship experience report]. Psicologia em Estudo, 22(1), 107-115. https://doi.org/10.4025/psicolestud.v22i1.31794

Sampieri, R. H., Collado, C. H. \& Lucio, P. B. (2013). Metodologia

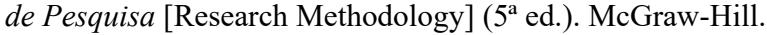

Semrud-Clikeman, M. (2007). Social competence in children. Springer.

Silva, T. A., \& Cavalcante, L. I. C. (2015). Habilidades Sociais e Características Pessoais em Escolares de Belém [Social Skills and Personal Features at Belém Students]. Psicologia: Reflexão e Critica, 28(4), 850-858. https://doi.org/10.1590/16787153.201528424

Streng, A., \& Kirk, S. (1938). The Social Competence of Deaf and Hard-of-Hearing Children in a Public Day-School. American Annals of the Deaf, 83(3), 244-254. http://www.jstor.org/ stable/44391557

Stürmer, I. E., \& Thoma, A. D. S. (2015). Políticas Educacionais e Linguísticas para Surdos: discursos que produzem a educação bilingue no Brasil na atualidade [Educational and linguistic policies for the deaf: Discourses that produce bilingual education in Brazil today]. [Anais] Reunião anual da associação nacional de pós-graduação e pesquisa em educação 37, 1-15. http://37reuniao.anped.org.br/wp-content/uploads/2015/02/ Trabalho-GT15-4093.pdf

Wake, M., \& Carew, P. (2016). Science, not philosophy, will help deaf and hard-of-hearing children reach their potencial. Pediatrics, 137(1), 1-2. https://doi.org/10.1542/peds.2015-3443 